\title{
Formation of Mesoherpetobionts Communities on a Reclamated Coal Open Pit Dump
}

\author{
Sergey Luzyanin ${ }^{1, *}$, and Natalya Eremeeva $^{1}$ \\ ${ }^{1}$ Kemerovo State University, 650000, 6 Krasnaya st., Kemerovo, Russian Federation
}

\begin{abstract}
The structure of the mesoherpetobionts arthropod communities of the reclamated dump of the Krasnobrodsky coal pit (Kemerovo region, Russia) has been studied. It was established that the pioneer grouping of mesoherpetobionts arthropod represented by classes of Chilopoda, Arachnida and Insecta-Ectognatha has been formed on the dump for two years after the soil deposition. From the Arachnida, the species of the order Aranei are the most active in the stocking of the dumps. From the class Chilopoda, the species of Lithobiomorpha appear the first on the dump. Insects from the following three orders, Heteroptera, Hymenoptera and especially Coleoptera take the main part in the expansion of dumps and the formation of primary communities. Among the Coleoptera, the beetles of the family of Carabidae (44 species, dynamic density 22.9 specimens/10 trapped per day) dominate. From them, small or medium-sized species are mainly involved in stocking the dumps. There are significant differences in the complexes of ground dump carabid beetles in comparison with the control group, differing in species composition of dominant species, species richness and species diversity parameters.
\end{abstract}

\section{Introduction}

Kemerovo region (Russia), in which one of the world's largest coal basins is located, Kuznetsk (Kuzbass), is among the leaders in hard coal excavation. Recently, there has been an annual increase noticed in production volumes. So, according to the results of 2016, 227.4 million tons of coal were produced, which is $5.4 \%$ more than in 2015 .

The basic technology of excavating minerals is an open (career) method, which accounts for more than $64 \%$ of the total production. Such anthropogenic impact inevitably leads to negative consequences for the environment: disturbance of the soil cover and hydrological regime, pollution of the atmosphere with erosion products, dust and gas emissions, etc. In addition, the consequence of the activities of coal mines is the formation of a complex man-made relief, the elements of which are quarries and mined bulk dumps.

An important direction in reducing the impact of coal pits on the environment is the reclamation of disturbed lands. Succession shifts in such territories are accompanied first by the formation of primary microbes and phytocoenoses. Practically simultaneously technogenic substrata are populated by animals, as a rule, first of all microarhropods, and then larger invertebrates (mesoherpetobionts) [1]. This group of animals plays a huge role in the

*Corresponding author: sl_luzyanin@mail.ru 
circuit of substances of natural and anthropogenically transformed ecosystems. Biological and ecological diversity, the abundance of mesoherpetobionts arthropods are clear diagnostic signs of the ecosystem condition and the direction of the recovery process.

Studies of the organic communities formation patterns in conditions of technogenesis are becoming increasingly important to scientists. It should be noted that a significant part of the work is aimed at studying the ecological and faunistic features of certain groups of mesoherpetobionts only, such as ground beetles [2-6] and ants [7, 8]. At the same time, there are no data on the structure of the entire complex of mesoherpetobionts arthropods formed on young reclaimed dumps. Therefore, the purpose of our study was to study the structure of the population of mesoherpetobionts arthropods on young reclamated coal pit dumps.

\section{Materials and Methods}

Studies were conducted from May to August, 2016, at the Krasnobrodsky coal pit (Kemerovo region, Russia). The experimental site was started on a rocky dump (54 $14^{\prime} 48^{\prime \prime} \mathrm{N}, 86^{\circ}$ $45^{\prime} 91 " \mathrm{E}$ ), represented by loose quaternary deposits (brown clays and loess-like loams) with fragments of massive sedimentary rocks of coal-bearing suites (sandstones, siltstones, argillites, limestones). In 2014, it was reclamated, the technical stage of which provided for the smoothing of the dump slope and the application of potentially fertile rocks (PFR) with limited physical and chemical properties good for plant growth. The biological reclamation consisted of planting 5-6-year-old Pinus sylvestris L. seedlings. Nowadays, as a result of the natural distribution of herbaceous plants on the dump by ruderal and weed vegetation dominates represented by Convolvulus arvensis L., Carduus crispus L., Sonchus arvensis L., etc. Projective cover degree is not more than 5-7\%. There is no turfing.

As a control, a site unspoilt by the activity of the coal pit is selected, located $1 \mathrm{~km}$ west of the dump, which is a birchwood surrounded by grassy-cereal meadows.

The collection of material was carried out by the method of soil traps, which were ranged in a line of 10 pcs. with an interval of $10 \mathrm{~m}$. The line of traps was located along the top of the dump. The traps were inspected every 7-10 days. A 10\% solution of acetic acid was used as the fixing liquid.

The dynamic density of arthropods was expressed in the number of specimens per 10 trap-days (specimens / 10 trapped per day (tpd)). In total, more than 80 samples were processed, over 5,500 individuals were counted.

Quantitative characteristics of the assessment of species diversity of the communities studied were carried out using traditional indices [9]. The following classes of ground beetle abundance are distinguished [10]: more than 5\% of the collections are dominant species, 1.1-5 are subdominant, $0.3-1$ are rare, and less than 0.3 are very rare.

When characterizing mesoherpetobia of model sites, the obtained structural and numerical indices of individual groups of arthropods were used, the correlation analysis (Spearman correlation) [9]. Mathematical data processing was carried out using Excel and Statistica 6.0.

\section{Results and Discussion}

The conducted research made it possible to state that during the first two years after the completion of dumping, along with the formation of phytocoenosis in the reclamated areas, a pioneer grouping of herpetobiontic arthropods is being formed. The arthropod stocking is a spontaneous way - by the migration of native species from the nearest biocenoses. At the earliest stages of the dump succession, the population of mesoherpetobionts is formed, 
consisting of only three groups of arthropods: arachnids, centipedes and insects (Figure 1), while in the control zone, in addition to the aforementioned groups of arthropods, Crustacea (cranberry), as well as a few representatives of the Mollusca type, were also found. The total dynamic density of arthropods in young dumps (44.29 \pm 6.35 specimens/ 10 tpd) was significantly lower in comparison with the control site $(181.99 \pm 10.90$ specimens / 10 tpd $)$ (for $\mathrm{p}<0.05$ ).

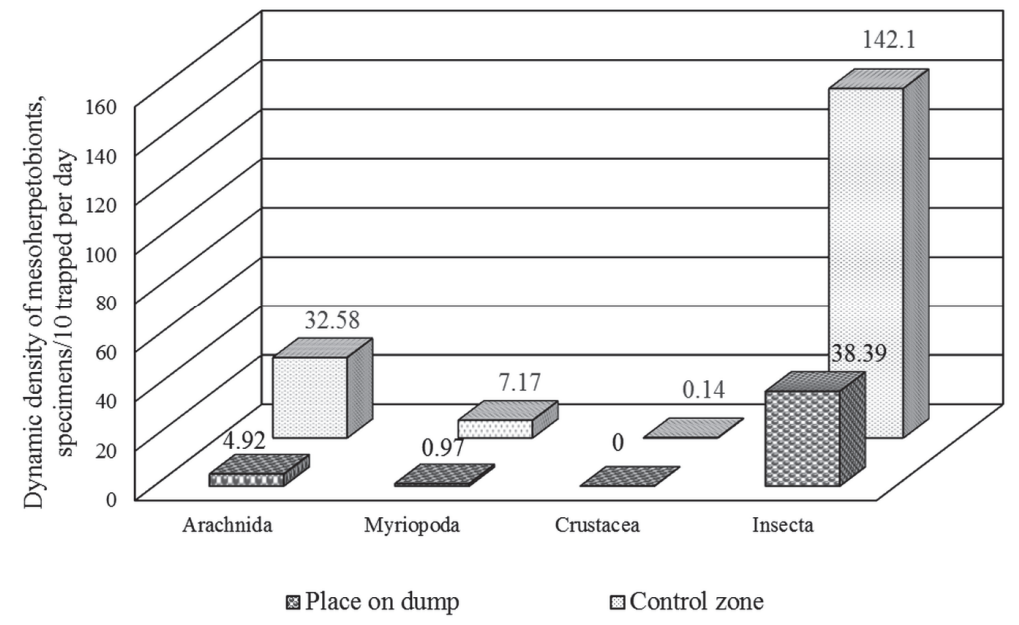

Fig. 1. Dynamic density of different groups of arthropods on the reclamated dump and in the control zone, specimens / 10 tpd.

From Figure 1, it can be seen that very low values of the dynamic density of all the detected groups of arthropods (millipedes -7.4 times lower, arachnids -6.6 times, insects 3.7 times) are noted in the dump in comparison with the control. Moisture-loving arthropods, crustaceans from the order Isopoda and wood lice, are very few in the control, and are not found on the dump.

Insects take an active part in the primary succession. They account for $86.7 \%$ of the total collection of all arthropods. This group of arthropods is also numerous in the control zone (78.1\%).

The density of the population of the second largest group, arachnids, was 7.8 times lower in the dump than that of insects (in the control 4.4 times less compared to insects). From the class Arachnida, representatives of three orders are noted on the dump: Acariformes, Opiliones and Aranei. Of these, spiders take the largest part in the development of new biotopes. The dynamic density of their population on the dump is 3.46 \pm 0.76 specimens / 10 trapped per day ( $70.4 \%$ of the total collection of all arachnids), in the control area $-21.10 \pm 2.58$ specimens / 10 trapped per day $(64.8 \%$ of the total collections of all arachnids). Daddy-long-legs and acariform mites on the dump are less common than in the control zone. For example, a very low population density of acariform mites was recorded on the dump $-0.98 \pm 0.71$ specimens / 10 trapped per day $(19.9 \%$ of the total collections of all arachnids) compared to the control $-10.40 \pm 1.86(31.9 \%)$. The most conservative group of arachnids is the daddy-long-legs, the average dynamic density of which on the dump is $0.48 \pm 0.20$ specimens / 10 tpd $(9.7 \%$ of the total collections of all arachnids), in control $-1.07 \pm 0.20$ specimens / 10 tpd (3.3\%).

The dynamic population density of Myriopoda was even more significantly different from that of the insects. On the dump, the density of their population was 39.6 times less 
compared to the insects, and 19.8 times in the control. The most mobile representatives of centipedes Chilopoda participate in young dumps stocking, while in the control, there are also representatives of another class - Diplopoda. From the Diplopoda class, the representatives of the order Julida were found on the model sites and the Lithobiomorpha order from the Chilopoda class.

The dominant group of mesoherpetobia, insects, is formed on the dump only by species from the class of Insecta-Ectognatha, while in the control there are representatives of two classes - Insecta-Entognatha and Insecta-Ectognatha. From the Insecta-Entognatha class, the species of the Collembola are marked in the control zone (Table 1).

Table 1. Dynamic density of orders of insects on the reclamated dump and in the control zone, specimens / 10 tpd.

\begin{tabular}{|c|c|c|}
\hline Detachment & Place on dumps & Control place \\
\hline \multicolumn{3}{|c|}{ Insecta-Entognatha } \\
\hline Collembola & - & $3.37 \pm 0.76$ \\
\hline \multicolumn{3}{|c|}{ Insecta-Ectognatha } \\
\hline Heteroptera & $6.42 \pm 1.26$ & $2.59 \pm 0.57$ \\
\hline Coleoptera & $30.16 \pm 4.26$ & $66.79 \pm 4.67$ \\
\hline Hymenoptera & $1.82 \pm 0.86$ & $69.35 \pm 7.48$ \\
\hline Total insects & $38.39 \pm 5.42$ & $142.10 \pm 9.71$ \\
\hline
\end{tabular}

In succession changes on the reclamated dump, insects of three orders from the class of Insecta-Ectognatha: Heteroptera, Coleoptera and Hymenoptera (Table 1) take part. From these, the basis of the pioneer grouping of mesoherpetobia is Coleoptera, accounting for $78.6 \%$ of all insect collections on the dump. In the control zone, the role of two orders Coleoptera and Hymenoptera - is significant. The number of these detachments is not significantly different; they account for $95.8 \%$ of total insect collections.

The Hymenoptera order on the dump is mainly represented by various species of ants from the family Formicidae: the genera Lasius, Myrmica, Formica and Tetramorium. The ants of the genus Camponotus are noted only in control. The most active in the settlement of the dump are ants of the genus Tetramorium, for which arid and highly heated areas of reclaimed dumps are optimal for life. The ants of this genus account for $62.4 \%$ of the total gathering of ants on the dump, while on the control plot it is only $0.2 \%$. The ants of the Myrmica family dominate in the control (87.6\%).

The pioneer grouping of the Coleoptera order on the dump is represented by the families Carabidae, Silphidae, Staphylinidae, Elateridae, Histeridae, Byrrhidae, Curculionidae (genus Otiorhynchus Germ.). In the control, a greater variety of Coleoptera was noted; there are beetles of three more families - Scarabaeidae, Dermestidae, Tenebrionidae. The dynamic density of Coleoptera on the heap is $30.16 \pm 4.26$ specimens / $10 \mathrm{tpd}$, which is 2.2 times less than the values in the control section.

In the first stages of succession changes in the dump and in the control zone, two families dominate in dynamic density: Carabidae and Staphylinidae (Figure 2), accounting for $90 \%$ of total beetle collections in the dump and $86.1 \%$ in the control.

The most significant contribution to the stocking of the reclamated dump is made by predators, ground beetles, one of the dominant groups of invertebrate animals of natural and anthropogenically transformed terrestrial ecosystems. Due to their biological and ecological characteristics, as well as a good ability to react to changes in the ecological situation, they have long been used as bioindicators of the condition of man-made territories. 


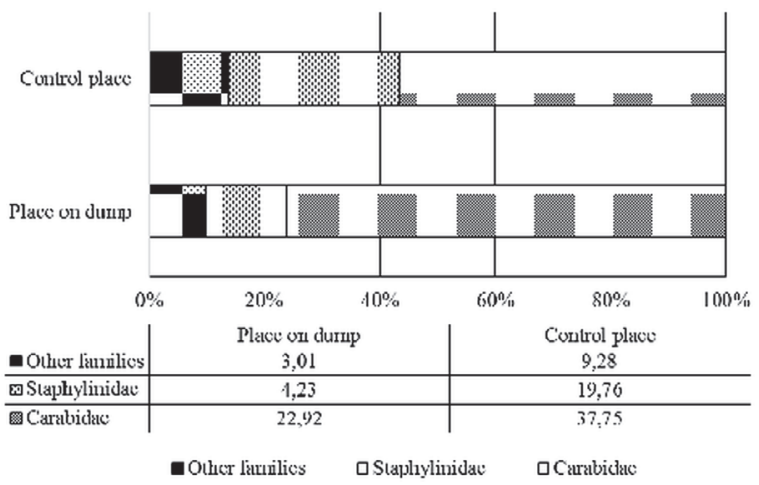

Fig. 2. The ratio of the dynamic density of the dominant families of coleopterans on the dump of the Krasnobrodsky coal pit and in the control zone, \%.

Note. The data table shows the dynamic density of Coleoptera, specimens / 10 tpd

The carried out investigations made it possible to identify 68 species of ground beetles of 24 genera, 16 tribes, 10 subfamilies. The structure of carabidocomplexes of model sites is dominated by rare species, a significantly smaller number of species of medium abundance and few dominant species. The detailed quantitative characteristics of the species structure of ground beetles are given in Table 2. As it can be seen from Table 2, the area of the young dump compared to the control zone differs significantly in species diversity and abundance of carabids; the value of the Chekanovsky-Sorensen index is only 0.13 (i.e., the similarity of the species composition of these plots is $13 \%$ ).

Table 2. Some indicators of the structure of the population of ground beetles in the territory studied.

\begin{tabular}{|l|c|c|c|}
\hline \multicolumn{1}{|c|}{ Indexes } & Designation & Place on dumps & Control place \\
\hline $\begin{array}{l}\text { Total number, (speci- } \\
\text { mens) }\end{array}$ & $\mathrm{N}$ & 1353 & 1379 \\
\hline Wealth of species & $\mathrm{S}$ & 44 & 33 \\
\hline $\begin{array}{l}\text { Margalef diversity } \\
\text { index }\end{array}$ & $\mathrm{K}$ & 0.52 & 0.48 \\
\hline $\begin{array}{l}\text { Margalef richness } \\
\text { index }\end{array}$ & $\mathrm{D} \mathrm{Mg}$ & 5.96 & 4.42 \\
\hline $\begin{array}{l}\text { Shannon diversity } \\
\text { index }\end{array}$ & $\mathrm{H}$ & $2.72 \pm 0.11$ & $0.65 \pm 0.07$ \\
\hline $\begin{array}{l}\text { Pielou's evenness } \\
\text { index }\end{array}$ & $\mathrm{e}$ & 0.71 & $0.32 \pm 0.014$ \\
\hline $\begin{array}{l}\text { Simpson's dominance } \\
\text { index }\end{array}$ & $\mathrm{C}$ & $0.1 \pm 0.002$ & \\
\hline $\begin{array}{l}\text { Chekanovsky- } \\
\text { Sorensen index }\end{array}$ & $\mathrm{I}_{\mathrm{CS}}$ & \multicolumn{2}{|l}{} \\
\hline
\end{tabular}

Analyzing the species composition of ground beetles in the areas under consideration, it can be seen that small or medium-sized species are mainly involved in the expansion of dumps. From the tribe of Bembidiini, it is Bembidion quadrimaculatum quadrimaculatum (L.) (dynamic density $5.27 \pm 1.66$ specimens/ 10 tpd), Zabrini - Amara ingenua (Duft.) (3.14 \pm 1.77), Harpalini - Anisodactylus signatus (Pz.) (1.97 \pm 0.92$)$, Harpalus rufipes $(1.59 \pm 0.62)$ (Deg.), Harpalus distinguendus distinguendus (Duft.) $(1,3 \pm 0,67)$.

Very interesting is the discovery on the dump of a new type of Calathus ambiguus ambiguus Pk., for Kemerovo region, whose dynamic density was $0.015 \pm 0.015$ specimens/ 10 
tpd. It is a subarid western Palearctic species. Previously, in Western Siberia, the species was known only from the vicinity of Tyumen and the village of Verkh-Tula (Novosibirsk region). In addition, a fairly high dynamic density of the steppe species Harpalus nigrans (Mor.), very rare for Western Siberia, is recorded here (dynamic density $0.41 \pm 0.13$ specimens / 10 tpd).

On the control place, in contrast, the collection is dominated by ground beetles of large size characteristics, preferring forest biotopes. From the tribe Carabini - Carabus aeruginosus Fisch. (13.43 \pm 4.16 specimens / $10 \mathrm{tpd})$, C. regalis regalis Fisch. (3.85 \pm 0.99). In addition to these species, Pterostihus oblongopunctatus (F.) (0.39 \pm 0.15$), P$. magus magus Man, (3.19 \pm 0.48$)$, Zabrini - Amara communis (Pz.) (0.63 \pm 0.25$)$, Sphodrini - Synuchus vivalis vivalis Ill. (0.25 \pm 0.14$)$, Platynini - Agonum gracilipes (Duft.) (1.22 \pm 0.37) can be classified among the dominants of the tribe Pterostichini.

The analysis of the landscape-biotopic distribution of carabides in the territory of the Kemerovo region in order to identify the most preferred biotopes, and also based on literature data, made it possible to combine the species of ground beetles marked in the studied area into six ecological groups (Figure. 3).

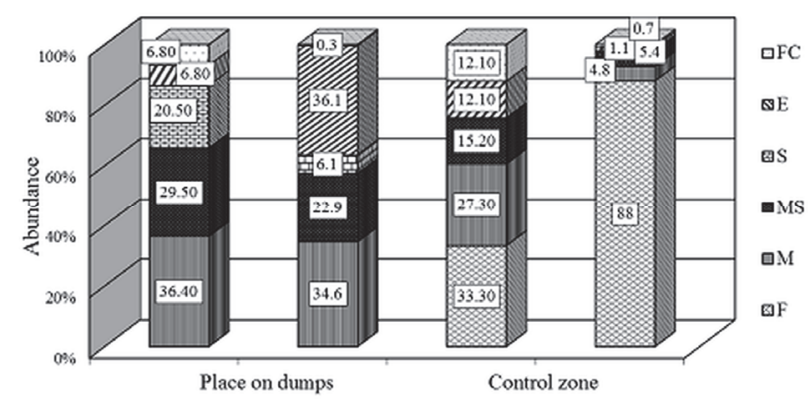

Fig. 3. Species (column 1) and numerical (column 2) abundance of ecological groups of ground beetles in the areas studied.

Note. FC - floodplain-coastal species, E - forest species, S - steppe species, MS - meadow and steppe species, $\mathrm{M}$ - meadow species, $\mathrm{E}$ - eurytopic species

As it can be seen from Figure 3 there is a clear tendency for the predominance of meadow, meadow-steppe and steppe groups, both in species and in numbers, on the dump, and there are no species of forest group on them. This is quite natural because on the dump there is scant vegetation, it is under prolonged exposure to insolation, which creates extremely arid conditions on its surface.

It is interesting to find three species of the floodplain-coastal group on the dump (Bembidion obliquum Sturm, Acupalpus meridianus (L.), Apristus striatus (Motsch.)), which prefer strongly or medium-humid areas, such as banks of water bodies, small rivers, streams etc. The dynamic density of these species is quite low $-0.025 \pm 0.02$ specimens / $10 \mathrm{tpd}$. Their presence is probably related to the periodic migration of ecosystems adjacent to the dump characterized by the presence of small streams.

Forest species, mainly representatives of the genus Carabus, were only encountered in the control. Remarkably, the species of eurytopic biotopic preferences are met at each site. An interesting fact is that there is a decrease in the relative abundance of representatives of this group as succession processes occur. From Figure. 3 shows that the maximum abundance of eurytopic species is noted on the young dump, which is primarily due to the large numerical abundance of the two species - Bembidion quadrimaculatum quadrimaculatum and Harpalus affinis (Schrank). 


\section{Conclusion}

Thus, the obtained results of the study show that carrying out remediation measures on the dumps of coal enterprises contributes to the rapid formation of the pioneer communities of herpetobionts, which take an active part in the further restoration of biocenoses disturbed.

Subsequent comprehensive studies of the succession processes of mesoherpetobia on the areas transformed by industrial activities will allow us to understand better the processes of formation and functioning of man-made landscapes, assess the suitability of new environmental conditions for coenoses formed, and develop recommendations for remediation work.

\section{Acknowledgement}

The reported study was funded by RFBR and Kemerovo Region according to the research project № 16-44-420211.

\section{References}

1. I.V. Zenkova, V.V. Kalmykova, A.A. Liskovaya, Eurasian Soil Sci., 42, 8 (2009)

2. I.Vowinkel, Hess. faun. Briefe, 8, 4 (1988)

3. C. Haag, M. Depenbusch, Mitt. Dtsch. Ges. allg. und angew. Entomol., 9, 4-6, (1995)

4. W. Durka, M. Brandle, M. Altmoos, Mitt. Dtsch. Ges. allg. und angew. Entomol., 11, 1-6 (1997)

5. E. Sigmund, W. Waitzbauer, Verh. Zool.-Bot. Ges. Osterr., 144 (2007)

6. S.L. Luzyanin, R.Yu. Dudko, A.N. Bespalov, N.I. Eremeeva, Euroasian Entomol. J., 14, 5 (2015)

7. J. Frouz, Sb. Okres. muz. Moste. R. prirodoved., 18 (1996)

8. L. Ottonetti, L. Tucci, G. Santini, Restor Ecol., 14, 1 (2006)

9. A.E. Magurran, Ecological Diversity and It's Measurement, (1988)

10. D. Mossakowski, Z. Wiss. Zool., 181, $3 / 4$ (1970) 
